as we know it in the London Basin. This will be seen on the publication of a paper which was sent in to the Secretary of the Geological Society on October Io last, but has not yet been put down by the Council for reading.

Wellington College, Berks, December 2.

A. IRVING.

\section{The Ffynnon Beuno and Cae Gwyn Caves.}

Mr. Worthington G. Smith's letter in NAture of December I (p. 105), is so misleading that I hope I may be allowed to reply to it. As is usual with highly prejudiced observers, he has attempted to prove too much for his case, as he might have seen had he taken the trouble to refer to my papers. The scraper which he mentions was submitted to Dr. John Evans for his opinion, and his conclusion as given in my paper in the Proceedings of the Geologists' Association, vol. ix. p. I 7, is as follows. The scraper " is not of a river-drift form, so far as at present known, but is precisely like many from the French caves of the reindeer periods, such, for instance, as La Madelaine." Mr. Worthington Smith's contention therefore that it agrees exactly with "the Neolithic scrapers of Icklingham and Mildenhall" can only prove that there is no chronological value in the classification of such implements. I must explain, however, that we have based no argument on the scraper reforred to, since it was found, before the explorations were properly commenced, in an open part of the cavern, and, as stated by me in the paper referred to, "it would be improper to dogmatize on this evidence." I may say at once that I entirely demur to any classification based on the form of the implements rather than on the fauna associated withs them, and I see no reason whatever to suppose that the worn, roughly-trimmed implements usually found in river gravels are older than the better-preserved flakes and trimmed implements found in caverns, which would be used for a different purpose from the rougher ones. The implements discovered subsequently belong to the so-called oldest types found in caverns, and were associated with Mammalian remains, equally characteristic of the oldest river gravels as of the caverns. Mr. Smith's statements in regard to the drift " in front of the Denbighshire caves" are of so extraordinary a character that I am tempted to ask him, before I criticize those statements, whether he ever visited the Fiynnon Beuno Caves during the course of the explorations, whether he ever saw the section of the drift exposed at the Cae Gwyn Cave, and what evidence he can bring forward to support his statements that the drift " is not in its original position, but distinctly and obviously relaid," and that he doubts " whether before it was relaic it was a true Glacial gravel at all?" I think the members of the British Association Committee, who have carefully conducted the explorations, and have the strongest evidence in support of their conclusion that the caverns, which are now about 400 feet above sea-level, were occupied by man and the animals before the marine drift and boulder-clay covered them over, have a right to ask for the data upon which such statements as those above referred to are based. These relate to facts, and must be dealt with in a different manner from those statements which are made clearly from a bias against the idea of Glacial and pre-Glacial man. Mr. Smith says that he has not been able to read up the literature of the subject, therefore he is probably unaware of the fact that Prof. Prestwich has recently (Quart. Journ. Geol. Soc. for August last) stated that he has arrived at the conclusion that the high-level gravels, with implements, in the valleys of the Somme, Seine, 'Thames, and Avon date back to Glacial or preGlacial times; and that "the great masses of gravel in the neighbourhood of Mildenhall and Lakenheath, also containing flint implements, are certainly n't of fluviatile origin "; and that they seem to him "to be part of the phenomena connected with the passage of the great ice-sheet over the eastern counties, and in that sense pre-Glacial."

Hendon, December 2.

HENRY HICKS.

\section{Cloud Movements in the Tropics, and Cloud} Classification.

A FEW months ago I called attention to the fact that the general movement of the upper clouds in the tropical regions of the Atlantic was from a westerly point; since then I have worked up all my observations (which extend over a period of
33I days spent in these regions in all months of the year except June) with the following results :-

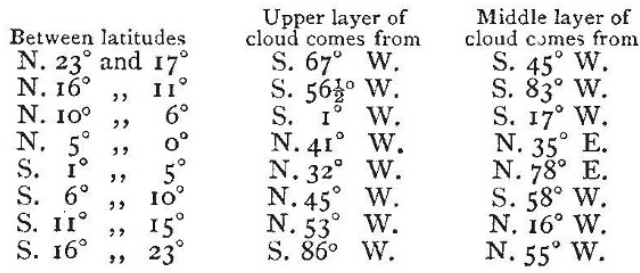

Taking a general mean for the whole region, this gives for the upper layer of clouds N. $86 \frac{1}{2}^{\circ} \mathrm{W}$, and for the middle layer of clouds $\mathrm{S} .73^{\circ} \mathrm{W}$. These results are from observations taken by myself, and no observation was registered if there was the slightest doubt as to the cloud movement. The ordinary ship register of upper cloud movements is worse than useless, a propagatory movement of the upper clouds being constantly mistaken for their real movement, and the names being hopelessly mixed, the cirro-cumulus being the source of most mistakes.

The cirro-cumulus exceeds all other forms of cloud in extent, ranging from the delicate fine mottles at a great elevation to the large flaky masses quite low down, and until it is considered a middle layer cloud we are certain to have some confusion.

It is quite time that cloud classification was placed on a more satisfactory basis. Now one observer will call a certain form of cirro-cumulus, a cumulo-cirrus ; a moderately high (middle layer) stratus of uniform texture, a cirro-stratus ; again, one form of low stratus, a pallio-stratus. Another observer will even call a detached fragmentary stratus, cirro-cumulus; and lots of observations will be useless from one observer failing to understand the particular form of cloud A calls pallio-stratus or B calls cirro-cumulus. Far better to keep to Luke Howard's simple nomenculature till some classification is definitely fixed to which all can agree.

To be satisfactory the classification must be founded on the physical and morphological (if I may use the word here) structure of clouds. I find no difficulty in making observers understand the difference between a stratiform and a cumuliform cloud; this is the first step, and once the distinction is thoroughly grasped the rest is comparatively easy. I propose something of this sort. Two orders, the "Stratiforms" and the "Cumuliforms," these to be subdivided into types, and these again into species; $e . g$. taking the ordinary dull-looking stratus commonly seen in anticyclonic areas, it would be described as--

$$
\begin{array}{lll}
\text { Order } & \ldots & \text { Stratus. } \\
\text { Type } & \ldots & \text { Low-stratus. } \\
\text { Species } & \ldots & \text { Pallio-stratus. }
\end{array}
$$

Or take that form of cirrus which appears as lines or threads right across the sky; it would be destribed thus-

$\begin{array}{lll}\text { Order } & \ldots & \text { Stratus. } \\ \text { Type } & \ldots & \text { Cirrus. } \\ \text { Species } & \ldots & \text { Cirro-filum. }\end{array}$

By using this system an observer would be gradually brought to recognize first the broad distinctions and then the minute distinctions in clouds. DAVID WILSON-BARKER.

\section{THE FORMS OF CLOUDS.}

$\mathrm{SO}$ much attention has been given of late years to the study of clouds, and so many names have been suggested by different writers for the saine form of cloud, that the whole question of cloud forms and cloud names must soon be referred to an International Congress. A few remarks on certain broad facts connected with the shapes of clouds, and on the fundamental principles by which weather forecasts are deduced from these forms, may therefore be acceptable to those who have not given special attention to the subject.

The two most important facts which must never be forgotten are: (I) that cloud forms are essentially the same all over the world; and (2) that there are only five or six distinct structures of clouds. 
The identity of cloud forms all over the world has recently been ciemonstrated both be. ore tle Royal Society and the Royal Meteorological Society of London by the

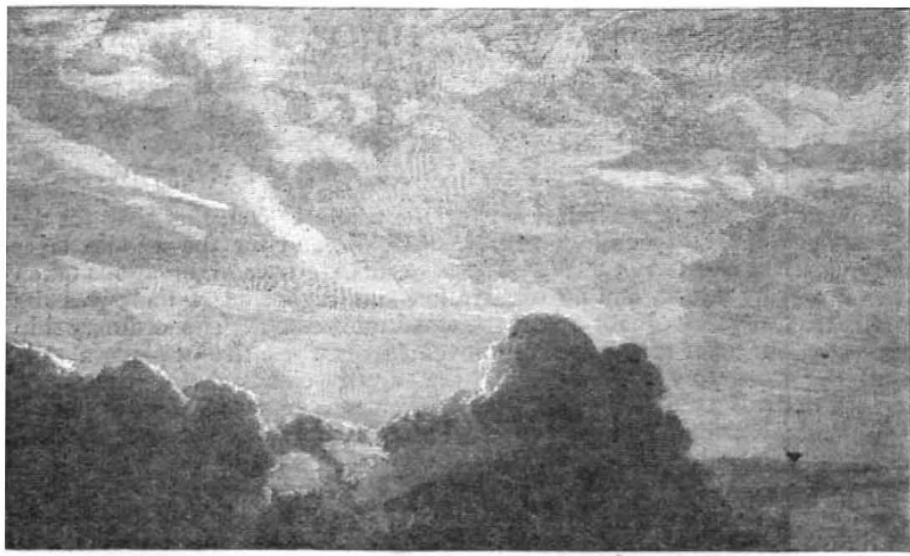

FIG. 1.-Cirrus wisp over cumulus. Folkestone.

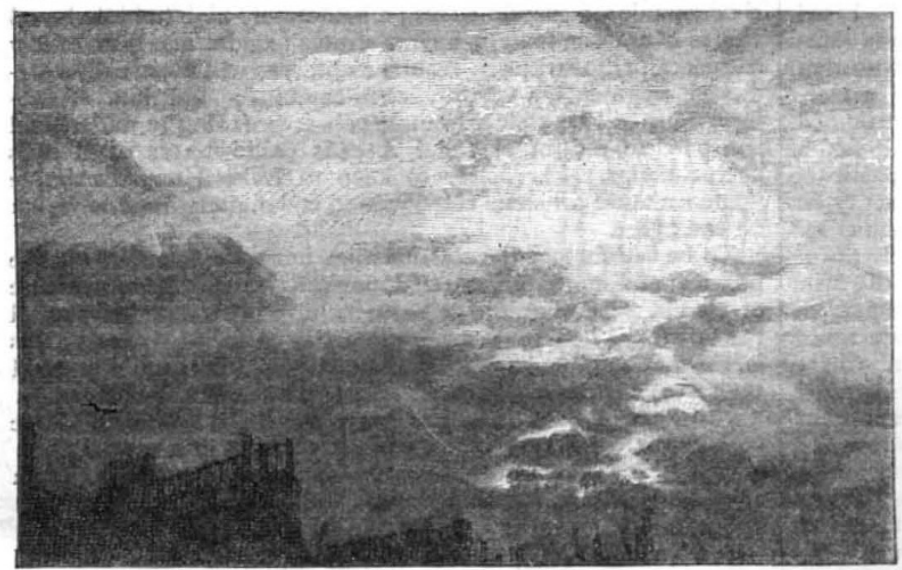

FiG. 2.-Stratus. London

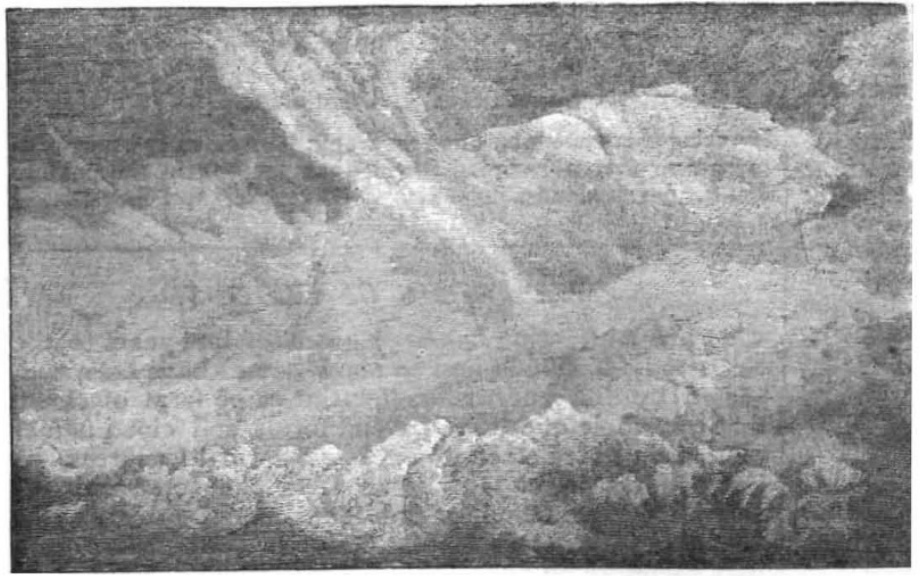

FtG. 3.-Cumulo-nimbus, cirrifying above. Bornes.

exhibition of about fifty photo raphs of clouds taken by the writer in various longitudes, and in latitudes ranging from $72^{\circ} \mathrm{N}$. to $55^{\circ} \mathrm{S}$. Some of these are reproduced in the illustrations of this article, and the conclusion of identity is irresistible. The cirrifying cloud over an irregular cumulus, in Fig. 3, might be seen over any summer thunderstorm in England, though this example is from tropical Borneo; while the fleecy cirro-cumulus in Fig. 4, which was taken near the Falkland Islands, about $51^{\circ} \mathrm{S}$., differs in no respect from the similar cloud we so often see at home. Fig. 6 is a stratocumulus from near Teneriffe, in the heart of thie North-east Trade; but the writer has seen an absolutely identical sky from the summit of North Cape, far within the Arctic Circle.

The different structures of clouds can certainly be reduced essentially to five or six types. A great deal must of course depend on the definition we adopt of a kind or species of cloud. We believe that one German meteorolngist in Rhineland says that he has discovered 30,000 different kinds of cloud, and that he has not yet finished his classification. This is absurd; for though no two clouds are ever exactly the same, any more than any two faces, still certain broad types of cloud structure can readily be recognized.

The first primary type of structure is the cirriform or hairy. The thin fibres of white silvery cloud which constitute a cirrus may assume an almost infinite variety of forms. The commonest is the simple wisp of white threads such as is shown in Fig. I, floating at a high level over a heavy mass of cumulus cloud. Sometimes the cirrus lies in long straight stripes, which Ley has shown have a great value in forecasting weather; or at other times assumes the "penniform" or plume-like appearance which, according to Vines, precedes a hurricane in the Antilles.

Cirrus as a rule is formed at very high levels-20,000 to 25,000 feet--and the constituent particles are undoubtedly frozen, but we occasionally find a fibrous structure at low levels, where the constituent particles are certainly in a fluid form. Both the cirrus and cumulus in Fig. $I$ are composed of icy particles, for the picture was taken on a cold winter day in England when snow showers were flying about. But in Fig. 3 we see a fibrous combed-out structure at quite a low level in Borneo, where the temperature both of the air and the rain makes it certain that the whole cloud mass was made up of liquid particles.

The true cumuloform structure of cloud can never be mistaken. The rising mass of condensed vapour assumes a rocky, lumpy appearance, which is well delineated in the lower portion of Fig. I. The varieties of form are infinite. Sometimes beautiful little isolated cloudlets, each with its.own flat base, float all over the sky, while at other times we only see mountainous masses rising above a gloomy cloud bank on the horizon, as in Fig. 3.

Essentially different from the above is the stratiform structure which is depicted in Fig. 2. Here we have a thin layer of flat cloud, at low level, more or less broken, but showing no trace of either a fibrous, rolled, or lumpy structure. When the sky is broken, this form of cloud is unmistakable, but when overcast it is impossible to dis- 
tinguish pure stratus from the flat under surface of some kinds of cumulus or nimbus.

The term nimbus is applied to any cloud which is precipitating rain. In practice we find two rather distinct types-a strato-nimbus or flat cloud, and a cumulo-nimbus or rocky rain-cloud. The former is characteristic of the rainfall in front of an extra-tropical cyclone, the latter of the precipitation from squalls and thunderstorms all over the world. Our illustration (Fig. 3 ) represents a distant view of the clouds over a thunderstorm in Borneo. Below we see the rocky summits of a mass of cumulo-nimbus, while apparently above, but really at about the same level, we find the characteristic fibrous structure that is called "goat's hair" by some, or "false cirrus" by others.

Another typical structure is that which has been called in all times by all nations fleecy, woolly, or some cognate name. In this, clouds assume the appearance of a fleece of wool. Each little mass of condensed vapour has a peculiar fibrous structure, quite different from true cirrus. The density and level of formation vary a good deal. When the cloud is thin at up to about 25,000 feet, most meteorologists call it cirro-cumulus; but when denser, and down at about i 8,000 feet, the name of cumulo-cirrus has been proposed to distinguish this low variety. Fig. 4 is an excellent specimen of cirrocumulus, from a photograph taken near the Falkland Islands

There is a form of cloud intermediate between pure cirrus and pure stratus which is so common and so characteristic of bad weather that it has universally been classified as cirro-stratus. We apply the term to a sky which is covered with a thin layer of cirrus fibres, more or less mixed up with a formle ss haze or veil of scattered ice-particles. Sometimes the cirrus threads are thin and white as the finest gossamer, and float 25,000 to 27,000 feet above the earth, but at other times the structure is coarser, and the level of formation not more than i 8 ,ooo feet. The first kind is called cirro-stratus, the second strato-cirrus. Fig. 5 is an example of a rather heavy cirro-stratus, taken near Dover. It will be observed that there are two distinct lines of structure about which the cloud masses are grouped, and that the lines intersect one another at a certain angle, so that the whole has a certain reticulated appearance. This is most characteristic of cirro-stratus.

Cirro-stratus with its hairy structure, and cirro-cumulus with its fleecy appearance, might at first sight appear to be radically different from one another; but they are not so really. It is by no means uncommon to see a patch of fibrous cirro-stratus suddenly become fleecy for a few minutes, and then return again to its former state. We cannot give the reason for this, as the origin of both structures is at present unknown.

Ther 2 is a form of cloud, intermediate between stratus and cumulus, to which the word strato-cumulus is appropriately applied.

In this the cloud layer is too lumpy to be called pure stratus, and not rocky enough to be called cumulus.

Fig. 6 is an excellent specimen of this type, t.zken near
Teneriffe; and here we see the lumpy masses of cloud getting apparently thinner and thinner as they approach the horizon, till they look at last like a scries of stripes or

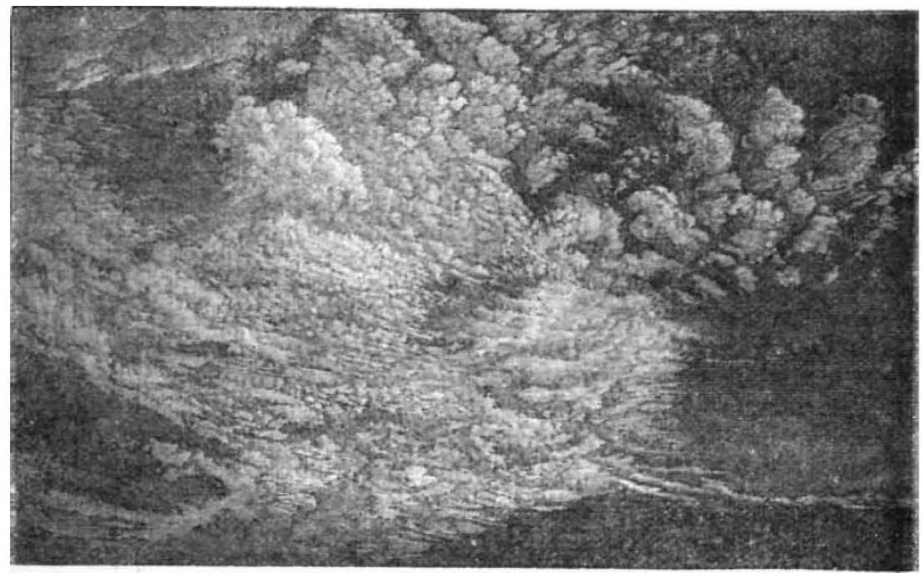

Fig. 4 -Cirro-cumulus, or fleecy structure. Falkland Islands.

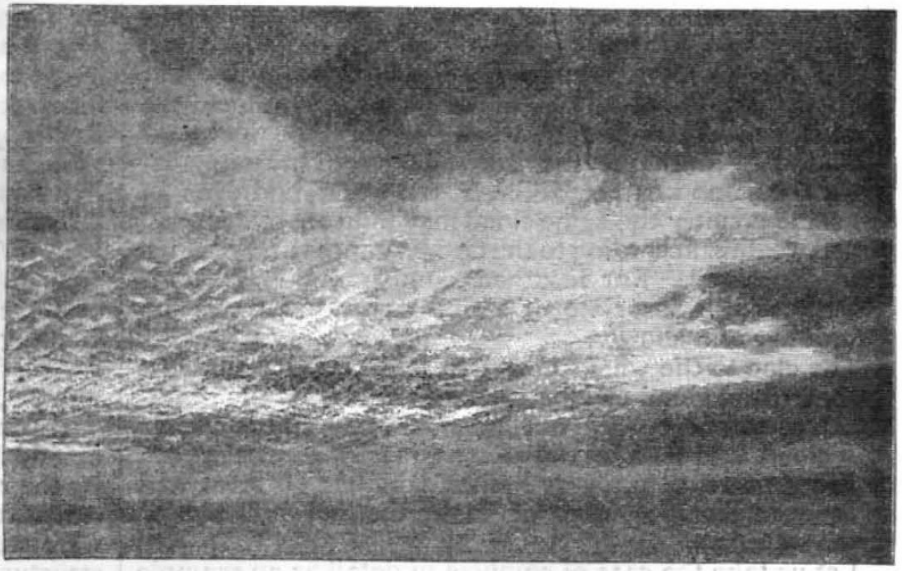

Fig. 5-Cirro-stratus. Folkestone.

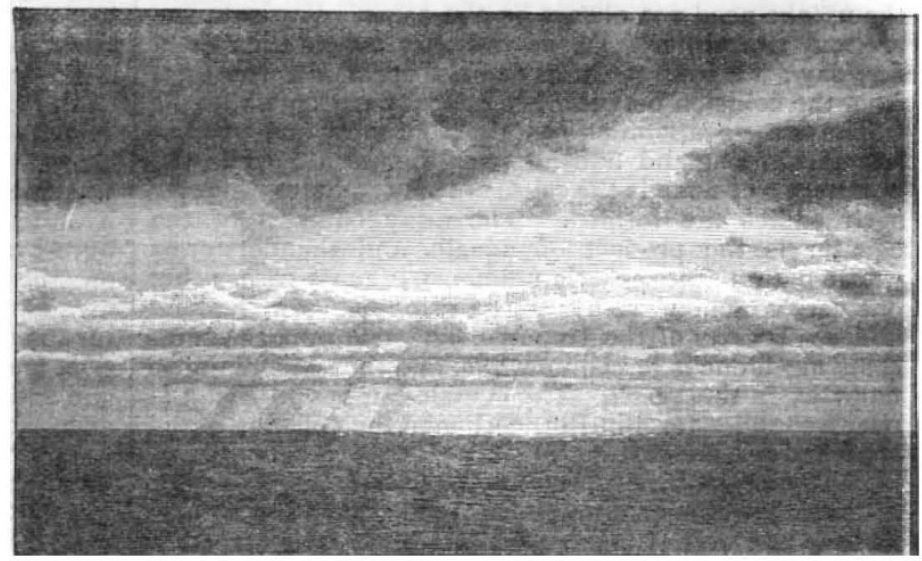

Fig. 6.-Strato-cumulus, Near Teneriffe.

rolls parallel to the horizon. This of course is the result of perspective.

The ten varieties of cloud which we have now described 
- cirrus, cumulus, stratus, nimbus and cumulo-nimbus, cirro-cumulus and cumulo-cirrus, cirro-stratus and stratocirrus, together with strato-cumulus-comprise all the important kinds of clouds; and there are really only five distinct types of structure-cirrus, stratus, cumulus, nimbus, and cirro-cumulus. Prof. Hildebrandsson and myself consider that the ten words above mentioned, compounded out of only four Latin words, are practically sufficient for all ordinary purposes.

Specialists in clouds will of course want more minute varieties, such as different names for some of the kinds of cirrus, and for the low broken clouds, such as scud, wrack, \&c. There are also a whole class of pendulous clouds, such as festooned stratus, pocky cloud, or mammato-cumulus; and the long black wreaths of cloud in front of certain types of thunderstorm, but these are all very local, and also very short-lived, so that they need only be mentioned here.

So far for the mere external forms of clouds as they would strike a savage or an artist ; but to the meteorologist there is a philosophy behind them. In England some forms presage wind and rain, others indicate the advent of fine weather; while recently it has been shown that different kinds of clouds are developed in different parts of cyclones and anticyclones. For instance, cirrostratus forms in front, cumulus in rear, of a cyclone; while fleecy cirro cumulus is very characteristic of the western side of the anticyclones.

But then we are met by the apparent paradox that precisely the same forms of cloud are found on the equator where neither cyclone nor anticyclone was ever developed. Moreover, the same cloud does not prognosticate the same weather all over the world, and even in the same country the same cloud may indicate either gnod or bad weather according to the circumstances under which it is developed. For instance, cumulus in England is sometimes the associate of a fine day, other times the forerunner of a shower.

The clue to the whole puzzle lies in the fact that the same form of cloud can be produced under totally different circumstances. Vapour-Iaden air can only condense into cloud, and then be drawn out or rolled about between different currents in a very limited number of ways, and hence the small number of really distinct varieties of cloud structure.

Let us take the case of cumulus in detail as an example of general principles. Cumulus is always the condensed capital of an ascensional column of air, but the source of the uptake need not always be the same. For instance, air may rise either (I) from ordinary evaporation on a fine day ; (2) from the uptake of a cyclonic vortex; (3) from the collision between two opposite currents.

The first-evaporation-is the source of fine-weather cumulus in England and all over the world; while the uptake of a cyclone is the cause of rainy cumulus wherever such eddies are formed. The rainy cumulus of the equator is the product of squalls and thunderstorms whose nature at present is unknown in most cases; but one very common cause is the collision between the land and sea breezes of the tropics. The two opposing currents meet, one is forced upwards, and then mountainous cumulus is the result. The cumulo-nimbus in Fig. 3 is over a thunderstorm in Borneo, due to the collision of the land and sea breezes.

All, therefore, that we can say for certain when we see a cumulus cloud is that an ascensional current of air has risen to the level of condensation. What future weather the cloud prognosticates depends on circumstances, and must be judged by our experience and knowledge of the climate in which we may happen to be. Clouds always tell a true story, but one which is hard to read; and the language of England is not the language of Borneo. The form alone only shows that a certain form of condens- ation is taking place; the true import must be judged by the surroundings, just as the sense of many words can only be judged by the context.

\section{RALPH ABERCROMBY.}

\section{FIFTH ANNUAL REPORT OF THE FISHERY BOARD FOR SCOTLAND.}

THE Report for 1886 contains so much of general interest that it deserves the attention of many who look upon a Blue-book as the driest of reading, only attractive to those whom it may immediately concern. It is desirable that the scope and practical aims of the Board should be more generally known, and the public should appreciate the excellent work done by it, instead of regarding this as the mere outcome of scientific leanings to certain lines of investigation. The fisheries of Scotland continue to be very productive, and nothing is more striking about them than the great and increasing yield of the herring fishery. Though this increase and the low price at which the herrings have been sold have proved a great boon to the community, especially to the poorer classes, it is deeply to be regretted that the crews sustained very heavy losses from the glutting of the market consequent on the large takes and low prices. A striking feature of the summer herring fishery of 1885 was that many in-shore grounds where herrings had been found in great abundance in previous years but which had been recently all but deserted were restored to their former fertility. This was even more marked in the season of I 886, as all along the east coast from Montrose to the Pentland Firth there seemed to be one immense unbroken shoal of herrings, lying from one to ten miles off land. At no former period in the history of this fishery were the catches so heavy. The winter herring fishery on the east coast was the most productive ever known, yielding a total catch of $128,44 \mathrm{I}$ crans. The gross total value of the sea and salmon fisheries of Scotland for 1886 was $£ 2,550,778$ 8s. $3 d$.

During the past year the scientific work consisted chiefly in carrying on the trawling experiments required by the recent Act of Parliament (Sea Fisheries (Scotland) Amendment Act, 1885), but in addition investigations were made as to the development, artificial hatching, structure, and habits of the more important useful fishes. An important part of the inquiry as to the influence of trawling consisted in arranging to obtain statistics showing the quantities of fish landed from the restricted areas, and the conditions under which they were captured-an extremely difficult matter to arrange.

The Board's marine station at St. Andrews has again been under the direction of Prof. McIntosh, whose Report shows that important work on the life-histories and development of the food-fishes has been done at this station. by him and Mr. E. E. Prince, by Dr. Scharff on the intra-ovarian eggs of food-fishes, and by Mr. Wilson on the development of the common mussel. The memoir first mentioned, viz. that on the development and life-histories of the food-fishes, is now ready for publication, and is illustrated by thirty-one quarto plates. Its size and the nature of the illustrations of course render it unsuitable for a Parliamentary Blue-book.

The "Report on the Trawling Experiments on the East Coast, Part I. Preliminary," by Prof. Ewart and Sir J. Ramsay Gibson-Maitland, gives the results of an important item in last year's work. The Act already referred to having empowered the Scotch Fishery Board to frame by-laws for the better regulation of sea-fishing, and one such law having been framed, passed, and confirmed, it was necessary to make arrangements to discover, if possible, what influence the prohibition of trawling under the by-law would have in leading to 